\title{
Clinical and Seroprevalence of Beta Haemolytic Streptococci in South India
}

\author{
Vidyavathi B. Chitharagi ${ }^{1}$, Kavana B.S. ${ }^{1}$, Morubagal Raghavendra Rao ${ }^{1 *}$, \\ Ranjitha S. Gowda ${ }^{1}$, Rashmi P. Mahale ${ }^{1}$, Sowmya G.S. ${ }^{1}$ and Anitha T.K. ${ }^{2}$ \\ ${ }^{1}$ Department of Microbiology, JSSMC, JSSAHER, S.S. Nagar, Mysore - 570 015, India. ${ }^{2}$ Department of Microbiology, \\ Kanachur Medical College, Mangalore, India.
}

\begin{abstract}
Beta Hemolytic Streptococci are the most causative agents of pharyngitis, tonsillitis and pyogenic skin infections, to severe invasive conditions like necrotizing fasciitis and meningitis. Though Group $A$ is more predominant streptococci causing disease, Group B, Group C Streptococcus (GCS) and group G Streptococcus (GGS) Group F Streptococci are emerging pathogens. Development of antibiotic resistance among them is a major concern now. This study aimed to know serogroup of beta hemolytic Streptococci causing infection and to know antibiotic resistance pattern. Based on standard biochemical tests, beta hemolytic Streptococci were identified and serogrouping was done using commercial latex test kit. Antibiotic susceptibility was performed as per CLSI guidelines. Among 120 beta hemolytic Streptococci isolated, 63 consecutive Beta hemolytic Streptococci were subjected for serogrouping. Group A were 35(55.6\%), 4 Group B, 9 Group C and F, 5 group G Streptococci. Among the 63 isolates majority of isolates were from throat swab 21(33.3\%) followed by pus 18 (28.5\%). BHS from sputum were 8 and 7 from endotracheal aspirates. All the isolates were sensitive to penicillin, $27 \%$ of the BHS were resistance to erythromycin. Information regarding the prevalent Streptococci in local geographical area is of great importance as non GAS groups are associated with severe skin and soft tissue infections. Another major concern is antimicrobial resistance among these serogroups. Knowing antibiotic susceptibility patterns helps in selecting appropriate antibiotic for effective management of these clinical conditions.

Keywords: Beta haemolytic, Serogroup, Streptococci, resistance.
\end{abstract}

*Correspondence: getdrraghurao@yahoo.com, +91-9902555558

(Received: 23 January 2019; accepted: 11 March 2019)

Citation: Vidyavathi B. Chitharagi, Kavana B.S., Raghavendra Rao M., Ranjitha S. Gowda, Rashmi P. Mahale, Sowmya G.S. and Anitha T.K., Clinical and Seroprevalence of Beta Haemolytic Streptococci in South India, J Pure Appl Microbiol., 2019; 13(1):581584 doi: 10.22207/JPAM.13.1.66

(c) The Author(s) 2019. Open Access. This article is distributed under the terms of the Creative Commons Attribution 4.0 International License which permits unrestricted use, sharing, distribution, and reproduction in any medium, provided you give appropriate credit to the original author(s) and the source, provide a link to the Creative Commons license, and indicate if changes were made. 


\section{INTRODUCTION}

Infections caused by beta haemolytic streptococci (BHS) range from mild, self limiting infections to the life threatening complications ${ }^{1}$. Lancefield's Group A and B are the predominant streptococci causing infections. Emerging major pathogens now are Group C Streptococcus (GCS), group $F$ and group G Streptococcus (GGS) which are associated with pharyngitis and other cutaneous infections. Development of antibiotic drug resistance among them is a major concern now. Group A have been associated with pyogenic and non pyogenic infections. Neonatal meningitis and pregnancy related infections are the major infections caused by Group B streptococci (GBS) ${ }^{2}$. Group F streptococci (GFS) are associated with suppurative infections ${ }^{3}$. Although resistance to penicillin in GAS is not documented, raising MIC value for penicillin has been reported and resistance to erythromycin, tetracyclines and other drugs have been on rise. Antimicrobial resistance among Non group A Streptococci are also increasing ${ }^{4}$. Thus, it is essential to know the serogroup of Streptococci causing infection and their antibiotic susceptibility to treat appropriately. Aims and Objectives

To isolate, identify beta hemolytic Streptococci from clinical samples sent for culture and to test antibiotic susceptibility pattern of the isolates.

To carry out Lancefield's serogrouping on beta haemolytic streptococci.

\section{MATERIALS AND METHODS}

This prospective study was conducted in the department of Microbiology, JSS hospital from January 2017 to December 2017. Beta hemolytic Streptococci isolated from different clinical specimens were further identified by biochemical tests. Gram stain was performed on all the isolates. Isolates were subjected to biochemical tests such as catalase, PYR, bile esculin, hippurate hydrolysis and CAMP test for further identification of group of streptococci. Antibiotic discs such as bacitracin (0.04 units) and trimethoprim and Sulfamethoxazole $(1.25 / 23.75 \mu)$ were used to identify Group A, group $C$ and group $\mathrm{G}$ streptococci.

Lancefield's serogrouping into A, B, C, D, $F$ and G Streptococci was done using "PLASMATEC streptococcal grouping latex test kit, United Kingdom. The plasmatic Streptococcal test kit is a rapid latex system used for determination of the six clinical groups of haemolytic Streptococci. Test was performed and interpreted as per the manufacturer's instructions.

Beta haemolytic Streptococci were tested to know antibiotic susceptibility pattern. Antibiotic susceptibility testing of the isolates was performed on Mueller-Hinton agar with $5 \%$ sheep blood by Kirby Bauer disc diffusion method. Anitbiotic discs tested were penicillin (10Units), erythromycin $(15 \mu \mathrm{g})$, ciprofloxacin, linezolid $(30 \mu \mathrm{g})$, clindamycin $(02 \mu \mathrm{g})$, chloramphenicol $(30 \mu \mathrm{g})$, tetracycline $(30 \mu \mathrm{g})$, vancomycin $(30 \mu \mathrm{g})$ and ceftriaxone $(30 \mu \mathrm{g})$. Erythromycin resistance detected as per the standard protocol by placing erythromycin and clindamycin discs at $20 \mathrm{~mm}$ apart

The plates are incubated in $5-10 \%$ $\mathrm{CO}_{2}$ at $37^{\circ} \mathrm{C}$ for 24 hours, and observed for the zone of inhibition and interpreted as per CLSI recommendations.

\section{RESULTS}

A total of 358 Streptococci were isolated from the total of 26,917 various clinical samples such as throat swabs, sputum, endotracheal secretions, broncho alveolar lavage, pus, blood, vaginal swab, urine and others. Of the 358 Streptococci, 156 were alpha haemolytic streptococci, 120 were beta haemolytic streptococci and 82 were non haemolytic streptococci. Among the 120 BHS, 63 consecutive Beta hemolytic Streptococci were subjected for Lancefields serogrouping. By Latex agglutination serogrouping, 35(55.6\%) were identified as Group A, 4 as Group B, 5 were group G Streptococci and 9 each detected as Group $C$ and F. Age of the patient ranged from 1 to 95 years of which maximum belonged to age group of 21-30 years $13(20.6 \%)$ followed by age group of $61-70$ with $12(19.1 \%)$. Out of 63 BHS 30(47.6\%) were isolated from female patients and $33(52.4 \%)$ from male patients.

Among the $63 \mathrm{BHS}$, maximum isolates were from throat swab $21(33.3 \%)$ followed by pus 18 (28.5\%). Eight BHS were from sputum and 7 from endotracheal secretions. Among the 63 isolates, the highest of 51 (81\%) samples were isolated from inpatients and $12(19 \%)$ were outpatient department. In Antibiotic susceptibility 
test pattern for the identified serogroups tested showed $100 \%$ susceptibility to penicillin, 60 $(95.2 \%)$ as sensitive to vancomycin. $46(73 \%)$ of the isolates were susceptible to erythromycin. Fifty nine isolates $(93.7 \%)$ were sensitive to both linezolid and ceftriaxone, 57(90.5\%) were sensitive to Ciprofloxacin. Susceptibility to tetracycline, clindamycin and chloramphenicol was seen in 55 (87.3\%), $54(85 \%)$, and $53(84.1 \%)$ respectively.

\section{DISCUSSION}

The beta-hemolytic streptococci (BHS) of various Lancefield groups are known to cause various systemic and localized infections worldwide. Group A Streptococci is known to cause serious complications like rheumatic fever, acute glomerulonephritis, toxic shock syndrome, necrotising fasciitis and scarlet fever in addition to milder infections. Similar infections can also be caused by Group $C$ and Group G. The occurrence of infections by non GAS is also being increasingly reported from elsewhere in the world and is now being the field of interest in the recent studies ${ }^{5}$.

In the present study, most prevalent serogroup was Group A Streptococci (55.6\%) followed by GCS and GFS group each with $9 / 63$ (14.3\%). A study conducted in north part of Karnataka reported GAS as predominant BHS than others where it accounted for $58.82 \%{ }^{6}$. Similar kind of study among pharyngitis patients in Iraq showed, $6.2 \%$ of their isolates belonging to group $\mathrm{C}$ and Group $\mathrm{F}^{7}$. While in a study by S. Rantala in Finland a predominance of GGS to GAS was recorded ${ }^{8}$.

In the study, most of the BHS were isolated from patients with age group 21-30 years with $13 / 63(20.6 \%)$ and $61-70$ years with $12 / 63(19.1 \%)$. BHS were isolated from males predominantly than females similar to other studies $^{9,10}$.

Among the 21 throat swabs sent for culture, GAS was isolated in 16/21 (76.19\%) and GCS in 5/21 (23.81\%) samples. Similar observation was made in study conducted in Salem and other parts of India ${ }^{11,12}$ An analogous study conducted in Assam, showed a high prevalence rate of GFS than GAS in throat swab cultures ${ }^{13}$. Another study by Majumdhar et al reported very low prevalence of GGS with only 4 in 1165 isolates ${ }^{14}$. This indicates that the prevalence of specific Lancefield groups of BHS can vary from place to place.

Present study showed GBS colonization in vagina in one pregnant woman. GBS causing skin and soft tissue infection accounted for $3 / 4$ (4.7\%) in the study whereas in other studies a rate of $11 \%$ has been documented ${ }^{10}$.

Study demonstrated $100 \%$ susceptibility to penicillin among all the BHS isolates which is in concordance with the most of the studies conducted worldwide ${ }^{5,6}$. In the study, $27 \%$ resistance was observed to erythromycin. Macrolide resistance has been on rise and our results are comparable to recent resistance reports from India ${ }^{4,10}$. The susceptibility to vancomycin was $95.2 \%$ by disc diffusion though was not confirmed by MIC testing. Study conducted in Andhra Pradesh, showed sensitive rate of $91.11 \%$ to vancomycin which shows comparatively increasing resistance rate in the $\mathrm{BHS}^{11}$. Susceptibility to linezolid and cipro-floxacin was more than $90 \%$ while published studies have reported $100 \%$ sensitivity to ciprofloxacin, and linezolid ${ }^{9,10}$. And penicillin remained as the most common antibiotic used for treatment of BHS in our study. Linezolid, was the second most antibiotic used for the treatment either alone or with the combination with other antibiotics.

\section{CONCLUSION}

The beta-hemolytic streptococci (BHS) of various Lancefield groups are associated wide variety of systemic infections worldwide. The incidence of non GAS are also increasing across the world causing different infections and antibiotic resistance detection should be routinely employed for early identification of drug resistance which further helps in preventing misuse of antibiotics and better management of patient.

\section{ACKNOWLEDGEMENT}

None

\section{CONFLICT OF INTEREST}

The authors declare that there is no conflict of interest. 


\section{REFERENCES}

1. Madeleine W. Cunningham at Department of Microbiology, "Pathogenesis of Group A Streptococcal Infections", Oklahoma. American society of Microbiology, 2000; 13(3): 470-511.

2. Narava, et al.: Prevention of perinatal group B streptococcal infections: A review with an Indian perspective. Indian Journal of Medical Microbiology, 32(1): 6-10.

3. Sixth Edition. Washington Winn,.Stephen Allen William Janda and et.al "Koneman's Color Atlas and Textbook of diagnostic Microbiology",

4. Capoor MR, Nair D, Deb M, Batra K, Aggarwal P. Resistance to erythromycin and rising penicillin MIC in Streptococcus pyogenes in India. Jpn J Infect Dis., 2006; 59: 334-6

5. Vanita Dhanda, Priyanka Chaudhary, Devinder Toor, Rajesh Kumar and Anuradha Chakraborti. Antimicrobial susceptibility pattern of beta-haemolytic group A, C and G streptococci isolated from North India. Journal of Medical Microbiology, 2013; 62: 386-393.

6. Trupti B Naik, Shobha D Nadagir and Asmabegaum Biradar. "Prevalence of Beta Hemolytic Streptococci Groups A, C, and G in Patients with Acute Pharyngitis", $J$ Lab Physicians, 2016; 8: 45-9.

7. Al-Charrakh,J. Al-Khafaji, and Rana, "Prevalence of beta haemolytic groups $\mathrm{C}$ anf $\mathrm{F}$ Streptococci in patients with acute pharyngitis". Journal of Medical Science, 2011; 3(3): 129-136.

8. Rantala S, Varkila V, Vuento R, Huhtala, Syrjanen
J. "Clinical presentations and epidemiology of $\beta$-haemolytic streptococcal bacteraemia: a populationbased study" European Society of Clinical Microbiology and Infectious Diseases. 2009

9. L.M Lamberstem and et al. "Nationwide laboratorybased surveillance of invasive betahaemolytic streptococci in Denmark from 2005 to 2011", Clinical Microbiology Infection, 2014; 20: 216-223.

10. Purva Mathur, Arti Kapil, .Bimal Das, Benu Dhawan and S.N. Dwivedi, Departments of Microbiology, AlIMS, New Delhi, India, "Spectrum of ג-haemolytic streptococcal soft tissue infections at a tertiary care hospital of north India" Indian Journal for Medical Research, 2003; 118: 187-191.

11. Pamu K and Kollapu L, India, "Isolation of -haemolytic Streptococci and Grouping by Enzymatic Extraction" J. Pharm Biomed Sci 2016, Volume 06, Number 09; Page 518-521

12. Navneeth BV, Ray N, Chawda S, Selvarani P, Bhaskar M, Suganthi N. "Prevalence of beta hemolytic streptococci carrier rate among schoolchildren in Salem" Indian J Pediatr., 2001; 68: 985-986.

13. Utpala Devi, Prasanta Kumar Borah and Jagadish Mahanta "The prevalence and antimicrobial susceptibility patterns of beta-hemolytic streptococci colonizing the throats of schoolchildren in Assam, India", J Infect Dev Ctries, 2011; 5(11): 804-808.

14. Majumdhar, Nilrathan and et.al, "The Prevalence of $\beta$-haemolytic Streptococcal infection among School children in Tripura, North East India",, Current Trends in Biotechnology \& Pharmacy, 2013, 7(4): 881-889. 